MATEC Web of Conferences 51, 03009 (2016)

DOI: $10.1051 /$ matecconf $/ 20165103009$

C) Owned by the authors, published by EDP Sciences, 2016

\title{
Investigation on Thermocompression Bonding Using Lead Free Sinterable Paste and High Lead Solder Paste for Power QFN Application
}

\author{
Gunaseelan Chandrakasan $^{1}$ and Mark Ovinis ${ }^{2}$ \\ 1,2 Universiti Teknologi PETRONAS, Malaysia
}

\begin{abstract}
Persistently growing Power QFN packages are used in various fields especially micro-electronics, aerospace, oil and gas as well. However, the particular industries is pushing forward to reduce the use of hazardous materials in the process of manufacturing and assemblies. Thermo-compression die-attach layer is perceived to be the most critical element in power QFN packages as the increase in operating temperature requires new materials with suitable thermo-chemical properties also with suitable melting points of next generation lead free die attachment material. In this situation, Hi-lead solder (RM218: Pb92.5Sn5Ag2.5) which known as high temperature material is widely being used in most semiconductor assembly for die attach, yet it deduce few reliability challenges like solder voids, the clip tilt performance and also solder splash which has been considered as major quality issue in assembly of Power QFN packages (FET die, IC die and clip attach). As a solution, sintering epoxy paste (SPC0733: $\mathrm{Sn} 96.5 / \mathrm{Ag} 3 / \mathrm{Cu} 0.5$ ) is being considered as a replacement. In this case, sintering epoxy paste demonstrating excellent electrical and thermal performance for Power QFN packages which is known to be demanded in market. Thus, this study investigates the differential pastes sintering paste and also solder paste, in order to identify best die attachment material to be used in thermo-compression bonding method. Therefore, the shear strength was resulting good indication where the sintering paste was recorded $2.4 \mathrm{Kg} / \mathrm{mm}$ meanwhile the solder paste was recorded $0 \mathrm{Kg} / \mathrm{mm}$ at peak temperature of $260^{\circ} \mathrm{C}$. Besides of that, the pot life seems promising as the sintering paste seems to have constant viscosity of $100 \mathrm{~Pa}^{*} \mathrm{~s}$ throughout the 48 hours tested while, high lead solder paste records viscosity from $100 \mathrm{~Pa}^{*} \mathrm{~s}$ marginally increase as the time increase which effects the inconsistency of pot life. Last but not least, the voids mechanisms proves sintering epoxy paste has the same pinhole voids as its individual, but the solder paste's pinhole voids are not same as individuals which easily can fail when the particular shear force was applied. Hence, sintering epoxy paste could resolve the quality issue by using thermo-compression bonding method and produce the better reliability than the solder paste.
\end{abstract}

\section{Introduction}

Power Quad Flat No-Lead (PQFN) package is also known as plastic package surface mounted with lead pads mounted on the bottom surface of the package [1]. PQFN packages is a unique as it will be in first choice because of its high speed application where high thermal performance is demanded in various industry. The assembly processes are simplified from the standard QFN assembly with only 
FET die, IC die and clip attach hence deduces an addition heat dissipation path to the top surface. In thermo-compression bonding the element that perceived to have high importance, ensure fixation of the die on its substrate as well as dissipation of the heat generated in the die [2]. There are essentially, several criteria that a material needs to have in order to be used for die-attach. The material should demonstrate high thermal conductivity, low coefficient of thermal expansion (CTE) mismatches between the die and the substrate, good wettability as well as adhesion to the die also the substrate, good mechanical properties with stress relaxation behaviours, good fatigue resistance, good corrosion resistance, good rework ability, high electrical conductivity and good reliability [3].

Currently, numerous studies were carried out in order to identify the most suitable material and techniques for die-attach. However, studies on identifying the materials with least disadvantages as well as most durable, with high melting point need to be done. Indeed, existing work and studies have disclosed the processes that includes solder alloys i.e. AuSn, PbSnAg, AuGe and AuSi as well as nano- and micro- particle sintering (regularly with Ag) apart from transit liquid phase bonding [3]. The former is divided into two categories, i.e. Transient Liquid Phase diffusion bonding (TLP) and sintered nanoparticles. TLP bonding using Ag-In can be done either as thin film layers or the mixture of particles. The ratio of Ag- to In- fundamentally, is chosen in such way so the end product will be in Ag- rich region. Meanwhile, the melting point of $\mathrm{In}$ - being as low as $156.6^{\circ} \mathrm{C}$ enables lower temperature processing. Sintered nanoparticle Ag die attachment is done with Ag nanoparticles in a paste with an average silver particle size of $30 \mathrm{~nm}$ [4]. On one hand, sintering process could be done at $285^{\circ} \mathrm{C}$ and the end product could withstand $400^{\circ} \mathrm{C}$. This is because the uniqueness in sintering process where it is an atomic diffusion process which avoids the liquid phase during the intermediate stage and thus the quality problems such as non-wetting, voids and many more can be eliminated. Besides, sintering particles basically are applied to delay the instruction of mass diffusion and eliminates densification diffusion at high temperature and melting point which able to stabilize according to process condition which leads to improved properties to support high temperature packages. On the other hand, being a single metal system, sintered Nano-silver will not have the intermetallic formation that leads to potential failure mechanism for multiple metal systems. Nevertheless, the occurrence of electrical migration and dry migration which cause $\mathrm{Ag}$ to build up at cathode in dendrites form that will reach the anode that will later cause failure of the device [5].

\section{Experimental}

The purpose of this experiment is to introduce new generation lead free die attachment material using thermo-compressive bonding method for Power Quad Flat No-Lead (PQFN) package. Suitable material and techniques for die-attach are quantified. This experiment exhibits the FET die, IC die and clip attach and lead frame. To analyze this experiment, an analysis phase will be conducted where die attach process tests including die shear test, die tilt test and SEM evaluation. The possible failure mechanism will be identified through these tests. Figure 1 shows the bonding diagram used in this study.

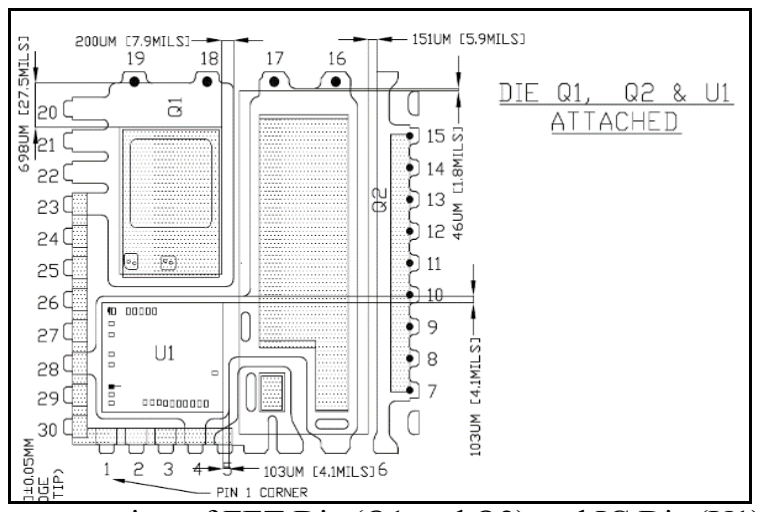

Figure 1. Bonding Diagram consists of FET Die (Q1 and Q2) and IC Die (U1) 


\section{A. Die Attach Materials}

Two different die attach materials were used, as described in below table:

Table 1. Die Attach Materials

\begin{tabular}{|c|c|c|c|c|}
\hline Sample & Type & $\begin{array}{c}\text { Thermal } \\
\text { Conducti } \\
\text { vity } \\
\text { (W/mK) }\end{array}$ & Powder & Composition \\
\hline $\begin{array}{c}\text { RM218 } \\
\text { (Hi lead } \\
\text { Solder) }\end{array}$ & Water clean & 25 & Type 3 & Pb92.5/Sn5/Ag2.5 \\
\hline $\begin{array}{c}\text { SPC073-3 } \\
\text { (Sintering } \\
\text { Paste) }\end{array}$ & No-Clean & 30 & Type 3 & Sn96.5/Ag3/Cu0.5 \\
\hline
\end{tabular}

\section{B. Process}

\section{i. $\quad$ Screen Print}

A stencil with a $2 \mathrm{~mm} \times 2 \mathrm{~mm}$ opening and a thickness of 7 mils for bottom print and 4 mils for top print was used for manually printing paste onto the DEK machine. Only single print deposit was employed. For each paste, five strips were prepared. Below Table describes the parameter used:

Table 2. Screen Print Parameter

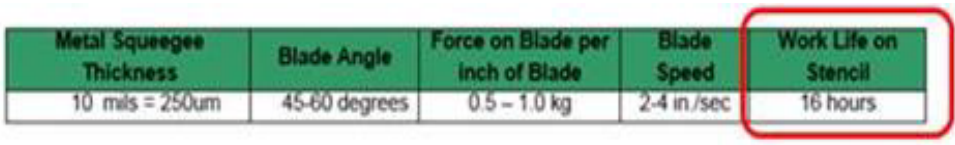

\section{ii. Die Attach}

The process of joining metal to metal which brought into atomic contact by applying force and heat simultaneously is known as thermos-compression bonding. The test dies and clips was kept on Nitrogen (N2) contained cabinet in order to avoid oxidization. For this experiment the test dies have been made in dices rather than full wafer formation. Then, the lead frame was placed on the hot plate with vacuum chuck. After that, the collet will pick up die with vacuum and proper alignment. The picked die will be brought into metal to metal contact when the desired pressure was achieved. However, as the pressure determined, the temperature will increase rapidly. Table 2 below presents the bonding conditions:

Table 3. Bonding conditions

\begin{tabular}{|l|l|l|l|l|}
\hline Die Attach Material & Bonding Time (ms) & Bond Force (g) & Peak Temperature(C) & Pressure (MPa) \\
\hline RM218 & 100 & 100 & 260 & 0.2 \\
\hline SPC073-3 & 100 & 100 & 260 & 0.2 \\
\hline
\end{tabular}

Machine ESEC 2000 had been used to perform pick and place process for the selected materials. 10 samples had been built using thermo-compression bonding. Thermo-compression bonding was experimented by varying the bonding time, temperature and pressure in order to achieve the quality of bonding. Yet suitable bonding time, peak temperature and pressure had been identified.

\section{iii. Reflow}

The strips were reflowed under air atmosphere via a MALCOM infrared oven. The profile with fixed. Peak temperature and soaking temperature were used. The Soaking temperature was $200^{\circ} \mathrm{C}$, while the peak temperature was $260^{\circ} \mathrm{C}$ with total time of $90 \mathrm{sec}$, respectively, as shown in below Figure (2):

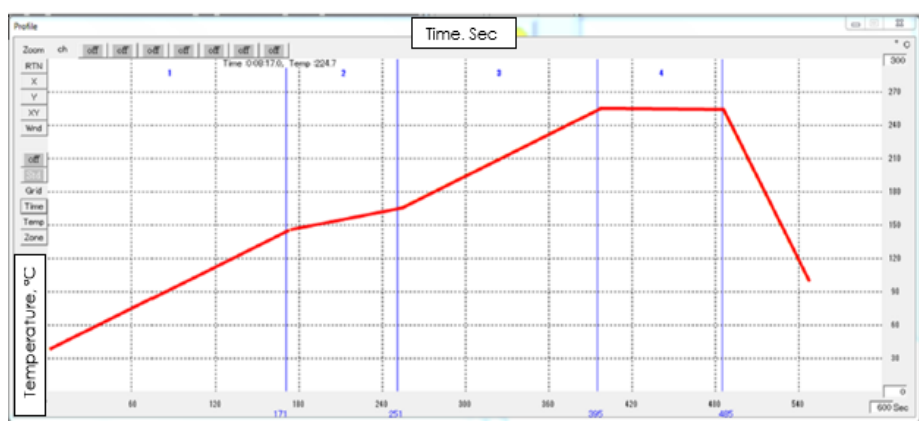

Figure 2. Reflow Profile 


\section{Results and Discussion}

Sinterable epoxy die attachment paste seems to be the best choice in building the Power QFN packages, as it is compatible with silver and gold die back, bare copper lead frames and also the PPF lead frames [6]. Besides that, TLPS materials can also basically issues system in package which having issues with solder such as solder voids, tilting, and others. Even though sinterable epoxy paste does not re-melt, it deduce some good criteria such as reliability and re-workability improvements.

\subsection{Hi lead Solder Paste Vs Sinterable Epoxy Paste}

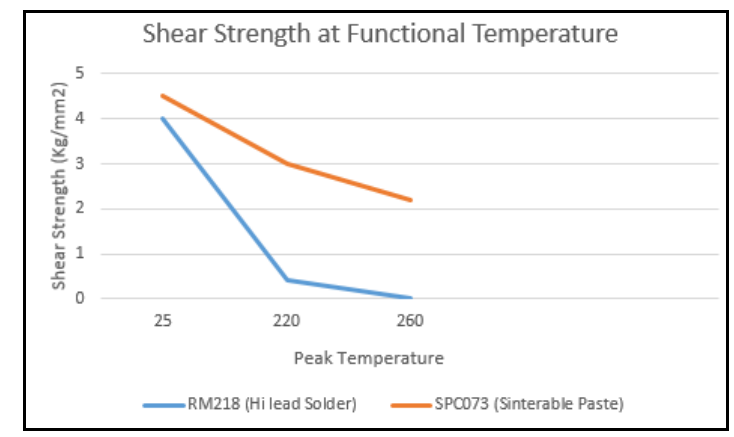

Figure 3. Shear Strength at Functional Temperature

Generally, shear strength defines the ability of die attaching material to withstand the separation between die and lead frame [6]. Hence, the functional temperature had been analyzed on above figure by varying from minimum to maximum peak temperature. For both die attaching material, it is known that minimum peak temperature is $25^{\circ} \mathrm{C}$ and the maximum is $260 \mathrm{C}$. It is also known that the peak temperature contributes to the shear strength of PQFN packages.

At minimum peak temperature of $25^{\circ} \mathrm{C}$, the sinterable paste was found to have high shear strength than the solder paste. At $220^{\circ} \mathrm{C}$, the shear strength seems to be dropped drastically, yet sinterable paste seems to be the lower drop than the solder paste which relies on huge gap. When reaching the maximum peak temperature at $260^{\circ} \mathrm{C}$, the solder paste seems to fail the shear strength as it records 0 $\mathrm{Kg} / \mathrm{mm}$ while sinterable paste records, $2.4 \mathrm{Kg} / \mathrm{mm}$. By means, sufficient force was applied to test the strength of the die. Subsequent strength explains an approximate indication of how well the die was attached on substrate. This clearly results the sinterable paste has the good wettability which joins the particles and melting with good condition.

\subsection{Pot Life at Room Temperature}

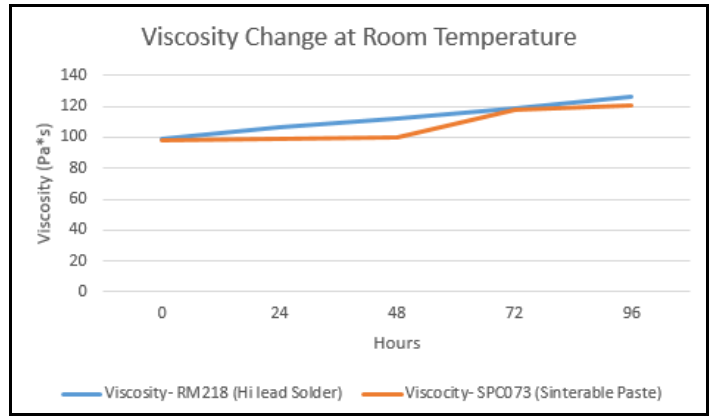

Figure 4. Viscosity Change at Room Temperature 
Viscosity change does affects the reliability of a Power QFN package, as the particles become non-reactive as the pot life at room temperature was not controlled. Thus, the SPC073-3 (sintering) paste storage need to be critically studied as it should be stored on laboratory bench top. However, the viscosity was measured at $25^{\circ} \mathrm{C}$ which known as room temperature and placed it $5 \mathrm{mins}$ on a parallel plate on Rheometer to stabilize the paste. Meanwhile, for RM218 (Hi lead) solder paste, the thawing time will be one hour as per the specifications and the stabilization will be placed on plate which rotates clockwise and anti-clockwise at $25^{\circ} \mathrm{C}$.

In this case, sinterable paste seems to have lower viscosity which was $120 \mathrm{~Pa}^{*} \mathrm{~s}$ at maximum reading of 96 hours, meanwhile, high lead solder paste records $129 \mathrm{~Pa}^{*} \mathrm{~s}$ at maximum reading of 96 hours. However, the graph illustrates, the viscosity is directly proportional to the hours of staging for both materials tested. This is a best characteristic in PQFN packages, as it relies lesser the viscosity, better the performance of the paste [6]. Thus, by comparison of both die attaching material, sinterable paste has stable viscosity change while the solder paste increase rapidly. It has been determined to maintain 24 hour for sinterable paste pot life, while solder paste may be the shorter pot life which also considering the cost of usage of die attaching material.

\subsection{Mechanisms behind Voiding}

Voids from volatiles is something common when the void structures defined where it's can be visualized in "wormy" condition. However, it can be eliminated or minimized with the adjustments with the certain conditions on reflow profile optimization [6]. Generally, when discuss about the reflow profile, the best profile is defined at ramp to peak temperatures. Considering the thermal mass of Power QFN, ramp to peak is often not the best option. Balance soak temperature to thermal mass and minimizing the total time to the peak temperature will results voids from volatiles can be eliminated or minimized drastically [7].Besides that, pinhole voids can be defined as tiny round voids. It may be the cause of time taken to melt the alloy particles in paste's was fast, as the fast melting time of alloy can reacts with the copper particles and preforms solidification condition. However, the late melting time of alloy particles joins the molecules but cannot lead to collapsing. In this case, these pinhole voids are generally non-contiguous and measured in the parameter of 15-25 micron in diameter.

Figure 5. Pinhole voids
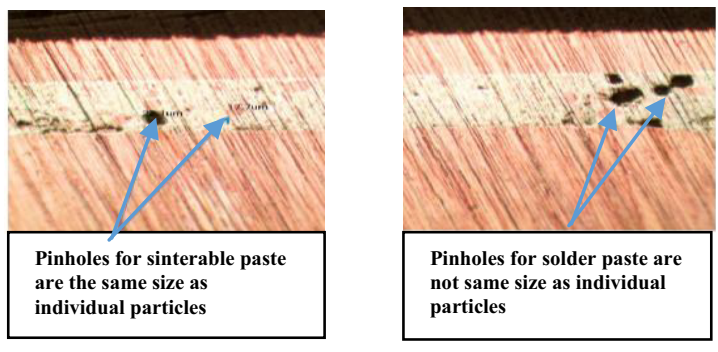

When discuss about the way of eliminate this void as it affects the joint strength, yet this cannot be eliminated through the process optimization as they are a normal feature of sinterable paste, as its alloy particles performance criteria need to be consider. At the same time, it is also known that the pinhole voids of sinterable paste were produced in the same size of holes throughout the unit. Meanwhile the pinhole voids hole size for solder paste was inconsistent, which can affect the joint strength.

\section{Conclusion}

SPC073-3 performed better than the RM218 solder paste at both room temperature and at $260^{\circ} \mathrm{C}$ for die shear test on bare die and also clip attach. However, sinterable paste is a high lead solder paste replacement as it consist of few advantages. For special case application like Power QFN packages 
solder paste deduce a lot of quality challenges as discussed above such as step soldering, no solder mask and others. Besides that, sinterable paste does not remelt or change footprint in reflow, which promising the stencil printing quality. Furthermore, the storage, shelf life, pot life and work life are comparable as well with the solder pastes [8]. Apart from that, mechanical, electrical and thermal performance are also seems promising and performs better than the solder joint [9]. Therefore, Sinterable paste is more reliable and can be classified as best die attaching material using the thermos compression bonding method. Therefore, other factors rather than die shear test, die tilt test should be considered in order to deduce a conclusion in this experiment. The major contributing factor to shear strength was the amount of die surface area that actually bonded on the substrate [10]. However, the pattern designed for this research seems successful as there was no die crack was occurred. The bond force applied on this research shall be quantified with different forces, to identify the failures of thermo-compression bonding occurs at which force. Besides that, the possible failures shall be researched in deep by varying more testing methods.

\section{References}

1. Bai, J. G., Zhang, Z. Z., Calata, J. N., \& Luo, G. Q. (2006). Low- temperature sintered nanoscale silver as a novel semiconductor device-metallized substrate interconnected material.IEEE transactions on components and packaging technologies, 29(3), 589- 593.

2. Buttay, C., Masson, A., Li, J., Johnson, M., Lazar, M., Raynaud, C., \& Morel, H. (2012). Die attach of power devices using silver sintering- bonding process optimization and characterization. http://hal.archives-ouvertes.fr/docs/00/67/26/19/PDF/article.pdf

3. Hui Shun Chin. "A Review on Die Attach Materials for SiC-Based High-Temperature Power Devices", Metallurgical and Materials Transactions B, 04/06/2010.

4. Edwards, C. \& Ho, B. (1999). Advanced packaging's step by step. San Diego: HIS Publishing Group. http://www.acoustech-inc.com/pdfs/Step\%20by\%20Step.pdf

5. H. Reichl, V. Grosser, "Overview and development trends in the field of MEMS packaging", MicroElectro Mechanical Systems, 2001. MEMS 2001, The 14th IEEE International Conference, pp. 1-5, 2001.

6. Harris, J. \& Matthews, M. (2009). Selecting die attach technology for high-power applications. http://www.ormetcircuits.com/d/bindocs/Selecting Die Attach Technology for High Power A pplications.pdf

http://www.ormetcircuits.com/d/parts/parts.php

7. Johnson, R. W., Zheng, P., Wiggins, A., Rubin, S., \&Peltz, I. (2007, September). High temperature electronics packaging proceedings. Presented at HITEN International Conference on High Temperature Electronics, St. Catherine's College Oxford, England.

8. Sabrina C., D.A. Vasilache, S. Girardi, P. Conci, and B. Margesin, "Thermocompression Bonding for 3D RF MEMS Devices Using Gold and Silver As Intermediate Layer", Proceeding of IEEE, 2(183-186).

9. Ohme, B., Johnson, B. J., \& Larson, M. R. (2007). SOI CMOS for extreme temperature application, Honeywell aerospace, defense\& space. Retrieved July 25 $5^{\text {th }}, 2014$ from http://www51.honeywell.com/aero/common/documents/myaerospacecatalogdocuments/Defense Brochuresdocuments/High Temperature/SOI_CMOS for_Extreme Temperature Applications.pdf

10. Henson, P. (2010). Considerations and options for high temperature die attach. https://etd.auburn.edu/bitstream/handle/10415/2249/final\%20Thesis.pdf 